1385cnt-2018-12-20_boletin-epidemiologico-vih-sida-its n35.pdf

6. Orientaciones internacionales para abordar la violencia de género en el ámbito escolar. París: ONU/UNESCO; 2019. [Acceso: 4 de octubre de 2019]. Disponible en: https: / / unesdoc.unesco.org/ark: / 48223 / pf0000368125/ PDF/368125spa.pdf.multi

7. Ministerio Nacional de Educación. Programa Nacional de Educación Sexual Integral. Lineamientos Curriculares para la Educación Sexual Integral Ley Nacional № 26.150. 2018. [Acceso: 4 deoctubre de 2019]. Disponibleen: https:/ / www. argentina.gob.ar/sites/default/files/lineamientos_0.pdf

8. UNESCO, Programa Conjunto de las Naciones Unidas sobre el VIH/SIDA, Fondo de Población de las Naciones
Unidas, Fondo de las Naciones Unidas para la Infancia, et al. International technical guidance on sexuality educationEvidence-Informed Approach. París: UNESCO; 2018. [Acceso: 1 de octubre de 2019]. Disponible en: https:/ / unesdoc.unesco.org/ark:/48223/pf0000260770

9. Tasker F. Lesbian mothers, gay fathers, and their children: a review. J Dev Behav Pediatr. 2005; 26(3):224-40.

10. Fondo de Publicaciones de las Naciones Unidas. Directrices operacionales del UNFPA para la educación integral de la sexualidad: un enfoque basado en los derechos humanos y género. Nueva York: UNFPA; 2014. [Acceso: 1 de octubre de 2019]. Disponible en: https:/ / www.unfpa.org/sites/default/files / pub-pdf/UNFPA_ OperationalGuidanceREV_ES_web.pdf

\title{
La nueva Nosología y clasificación de las displasias esqueléticas
} The new Nosology and classification of genetic skeletal disorders

En el último cuatrimestre de 2019, se presentó en el American Journal of Medical Genetics, la nueva clasificación y Nosología de las displasias esqueléticas, la cual es muy esperada por los clínicos y agrupan a estas entidades según el fenotipo y la base molecular. Por tanto, su naturaleza sigue siendo un sistema "híbrido" en el sentido que no siempre se basa en el mismo criterio. Algunas entidades están agrupadas de acuerdo al gen causal, otras comparten características radiológicas comunes, un curso clínico similar (letalidad) o afectación de partes similares del esqueleto.

Un grupo de expertos en Radiología, Cirugía Ortopédica, Pediatría y Genética se reunieron en París, hace cincuenta años y propusieron desarrollar la Nomenclatura Internacional de Enfermedades Constitucionales y Óseas, con el objetivo de alcanzar un acuerdo sobre los diversos trastornos esqueléticos. Estos presentaron una creciente evidencia en la heterogeneidad, siendo apreciado por la comunidad médica la cual comenzó a percibir la diversidad clínica y de los hallazgos radiológicos, quedando claro que no todas las personas con extremidades cortas tienen acondroplasia (OMIM 100800), e igualmente no todos los individuos con un tronco corto tienen el síndrome de Morquio o mucopolisacarisosis tipo IV (OMIM 25300 y 253010). Fueron diversas las reuniones hasta que treinta años después en 1999 se establece la Sociedad Internacional de Displasia Esquelética (ISDS, por sus siglas en inglés), cuyas revisiones de la nomenclatura (nosología) se delegaron a expertos del Comité nominados dentro del seno de la institución, que presenta una combinación de experiencia clínica, radiológica y genética. Los expertos fueron presentando sus revisiones y la última representa la décima edición de la Nosología y clasificación de los trastornos esqueléticos. ${ }^{1}$

Esta comprende 461 trastornos divididos en 42 grupos diferentes. ${ }^{1}$ La anterior clasificación (2015) fue de 436 con igual número de grupos, ${ }^{2}$ pero dos de ellos, el 18 y el 19 han cambiado de nombre. Los genes actualmente son de 437 en 425 trastornos que representan el $92 \%,{ }^{1}$ en comparación del $58 \%$ en el año $2006 .^{3}$

Se debe conocer que:

1. Variantes patogénicas en un gen puede causar varios fenotipos, por ejemplo: (grupo 1), llamado condrodisplasia FGFR3, conjunto de entidades producidas por mutaciones del gen FGFR3, y cuyas diferentes mutaciones (heterogeneidad genética alélica), pueden ocasionar la displasia tanatofórica tipo 1 y 2 (OMIM 187600 y 187601) respectivamente, la ya comentada acondroplasia, hipoacondroplasia (OMIM 146000), acondroplasia severa con retardo del desarrollo y acantosis nigricans, el cual recibe el acrónimo de síndrome de SADDAN, por sus siglas en inglés (OMIM 616482), camptodactilia, talla alta e hipoacusia, síndrome de CATSHL (OMIM 610474). Todos excepto este último presentan un patrón de herencia autosómico dominante, ya que el síndrome de CATSHL puede exhibir un patrón de herencia autosómico dominante o recesivo. Además de las entidades ya comentadas, 
33 distintas craneosinostosis sindromáticas como por ejemplo, el síndrome de LADD (OMIM 149730), y 41 fenotipos diversos se encuentran relacionado con mutación del gen FGFR3.

En el grupo 33, denominado síndromes de craneosinostosis, las craneosinostosis similar a Crouzon con acantosis nigricans (OMIM 612247), craneosinostosis tipo Muenke (OMIM 602849) y el fenotipo similar al síndrome de Saethre-Chozen, se deben igualmente a mutaciones en el gen FGFR3.

2. Un fenotipo puede ser causado por varios genes (heterogeneidad genética de locus), por ejemplo: (grupo 25), llamado osteogénesis imperfecta o disminución de la densidad ósea. La osteogenesis imperfecta tipo 1, no deformante con persistencia de escleras azules (OMIM 166200), puede ser causada por mutaciones en los genes COL1A1 o COL1A2, ambos con patrón de herencia autosómico dominante. Estos dos genes, además de los CRTAP, LEPRE1 y PPIB pueden ser responsables de la osteogénesis imperfecta tipo 2, forma perinatal letal (OMIM 166210, 610854, 610915 y 259440). Cuando se debe a los genes COL1A1 o COL1A2, se mantiene el patrón de herencia autosómico dominante, y en el resto de los genes descritos, el patrón de herencia es autosómico recesivo, y así sucesivamente con el resto de entidades que conforman este grupo.

Fenotipos que muestran heterogeneidad genética de locus, pero que son clínica y/o radiológicamente indistinguibles entre sí, se incluyen en la Nosología. Los ejemplos la displasia epifisaria múltiple con patrón de herencia autosómica dominante (grupo 10), enanismo primordial osteodisplásico microcefálico (grupo 19), condrodisplasia puntata rizomélica (grupo 21) y la osteopetrosis de forma infantil severa (grupo 23). ${ }^{1}$

Se han agregado nuevas entidades al (grupo 13) de displasia espondilo-epi-(meta)fisaria (DEEM), trastornos que estaban previamente mal definidos y clasificados como tipos desconocidos de DEEM. Por otro lado, la Nosología actual incluye el primer ejemplo de variante patogénica en un ARN mitocondrial, denominada displasia espodiloepifisaria tipo MIR140 (grupo 15). ${ }^{1}$

No cumplen criterios de inclusión por falta de compromiso esquelético significativo y por lo tanto, no se incorporaron a la clasificación algunas variantes patogénicas en los genes FGFR3, COL2A1, COMP, NPR2 y ACAN que pueden causar fenotipos leves, como talla baja aislada o enfermedad articular degenerativa prematura. ${ }^{1}$

Ejemplos de displasias esqueléticas previamente publicadas en Archivos Argentinos de Pediatría, por nuestro grupo de trabajo se encuentran, la displasia metatrópica (OMIM 156530), ${ }^{4}$ en el grupo 8, denominado TRPV4, cuyo nombre se debe al gen causal, incluye las formas hiperplásica "letal" y no letal. Por su parte, la exostosis cartilaginosa múltiple (osteocondromas) (OMIM 133700), ${ }^{5}$ en el grupo 29, denominado desarrollo desorganizado de componentes esqueléticos y producida por mutaciones de los genes EXT1 y EXT2. Finalmente, la displasia cleidocraneal (OMIM 119600), ${ }^{6}$ en el grupo 32, denominado displasia cleidocraneal y alteraciones relacionadas, producida por mutaciones de en el gen RUNX2. Todas estas alteraciones exhiben un patrón de herencia autosómico dominante.

No solo los genes que codifican proteínas específicas del tejido óseo son esenciales para la formación y mantenimiento del hueso y el cartílago, sino otras proteínas que tienen un papel más ubicuo, como un gen regulador de la transcripción, división celular o transporte intracelular son otra causa bien establecida de trastornos esqueléticos. Los avances en las técnicas de secuenciación (genoma completo o exoma) han resuelto dudas y han definido entidades dentro de estos grupos, además de conocer su etiopatogenia. Esta nueva Nosología puede servir como ayuda para el clínico, ya que muchas de estas entidades son de difícil diagnóstico y a través del mismo impartir un oportuno asesoramiento genético familiar. Además, así como facilitar el reconocimiento de nuevas entidades y fomentar la investigación.

\section{Dedicación}

A la Dra. Ana Bracho, Pediatra Genetista, Profesora de la Universidad del Zulia, quien entre diferentes asignaturas dicta la de displasias esqueléticas.

Prof. Francisco Cammarata-Scalisi

Unidad de Genética Médica. Facultad de Medicina. Universidad de Los Andes, Mérida, Venezuela francocammarata19@gmail.com

http: / / dx.doi.org/10.5546/ aap.2020.86

Texto completo en inglés:

http:/ / dx.doi.org/10.5546/ aap.2020.eng.86 
Cómo citar: Cammarata-Scalisi F. La nueva Nosología y clasificación de las displasias esqueléticas. Arch Argent Pediatr 2020;118(2):86-88.

\section{REFERENCIAS}

1. Mortimer GR, Cohn DH, Cormier-Daire V, Hall C, et al. Nosology and classification of genetic skeletal disorders: 2019 revision. Am J Med Genet A. 2019; 179(12):2393-419.

2. Bonafe L, Cormier-Daire V,HallC, Lachman R, etal. Nosology and classification of genetic skeletal disorders: 2015 revision. Am J Med Genet A. 2015; 167A(12):2869-92.
3. Superti-Furga A, Unger S. Nosology and classification of genetic skeletal disorders: 2006 revision. Am J Med Genet A. 2007; 143A(1):1-18.

4. Cammarata-Scalisi F, Matysiak-Scholze U, Heinze J, Barrera A, et al. Displasia metatrópica en una niña con mutación c.1811_1812delinsATenelexón11 delgen TRPV4noinformada previamente. Arch Argent Pediatr. 2015; 113(1):e10-3.

5. Cammarata-Scalisi F, Cozar M, Grinberg D, Balcells S, et al. Alelo doble mutante en el gen EXT1 no informado previamente en una adolescente con exostosis múltiple hereditaria. Arch Argent Pediatr. 2015; 113(2):e109-12.

6. Callea M, Fattori F, Bertini ES, Yavuz I, et al. Estudio clínico y molecular en una familia con displasia cleidocraneal. Arch Argent Pediatr. 2017; 115(6):e440-4.

\section{Archivos hace 75 años} Municipalidad de la Cindad de Buenos Aires.-Asistencia Pública -

E L L A C T A R I U M *

El hijo es dueño de la leche de su madre, el excedente es del Lactarium.

POR KL

Dr. SAUL ISABELINO BETTINOTT

La frase que subtitula esta comunicación la formuláramos hace ya tiempo como un distintivo del Lactarium Argentino. Fstamos casi convencidos que no es una írase más, o un comprimido de palabras. Representa un modo de ver, en un cierto aspecto de la asistencia social de la infancia.

Desde el año 1928 en que iniciáramos nuestra experiencia del Lactarium, hasta ahora, han transcurrido 16 años. Nos resolvemos hoy, y creemos que ya no es tarea prematura, a realizar una reseña sintética de la evolución gradual, sobretodo porque creemos que lo que fuera una ilusión antes, hoy parece ser una obra consolidada por su utilidad en el uso.

Definimos el Lactarium como una institución del estado, que sin fines de lucro tiene un propósito médico-social, cual es el de extraer, conservar y distribuir el excedente de leche materna evitando todos los inconvenientes de la lactancia mercenaria.

Siempre creímos que correspondía en naturaleza a las características de nuestro ambiente y que estaba en potencia en el pensamiento de los pediatras argentinos de la segunda década (1910-1920) Tan cierta es nuestra creencia, que la transcripción que a continuación hacemos, afirma un hecho más en cl conocimiento de esta obra médico-social que decimos que es argentina.

En el año 1919 se celebra en Montevideo el Segundo Congreso Americano del Niño. El pediatra argentino Delio Aguilar $^{1}$, hace una comunicación titulada "Lactación con leche de mujer, sin ama" Trans. cribimos un párrafo de este mencionado trabajo, se verá en él la síntesis del Lactarium.

Dice Aguilar "pero si por ejemplo, una mujer puede en determi"nadas circunstanciass vender su hermosa cabellera, o su exceso, en acto "más noble y útil resultaría que vendiera el exceso o el total, si no tiene "aplicación, de su leche, que al par que fuera la esencia de la vida de un "ser que periclita, pudiera llevar a su hogar el valor monetario de ella "para solventar necesidades apremiantes de otros niños a los cuales les

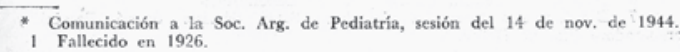

El texto completo se encuentra disponible en la versión electrónica de este número. 